\title{
Marine Current Turbines and Generator preference. A technology review
}

\author{
Astrid Røkke ${ }^{1}$, Robert Nilssen ${ }^{1}$ \\ ${ }^{1}$ Department of Electric Power Engineering \\ Norwegian University of Science and Technology \\ 7491 Trondheim, Norway \\ E-mail: Astrid.roekke@ntnu.no, Robert.nilssen@ntnu.no
}

\begin{abstract}
Marine current power is a significant energy resource yet to be exploited for electricity production. Several novel turbine technologies can be found on the market, and new ones emerge every year. This study found that the most popular choice seems to be the axial flow three-bladed turbine, although the industry has not yet converged to one preferred technology. An overview of the turbine technologies is presented with drive train layout for each device, if this information is obtainable. The majority of manufacturers use geared (mechanical or hydraulic) solutions, and an induction or a synchronous generator. The few direct drive systems all use PM synchronous generators. For prototype turbines there is a trade-off between choosing a proven generator technology that is not optimised for the application, and using a prototype machine that may reduce the number of design iterations.
\end{abstract}

\section{Key words}

Marine current, tidal, energy, generator, technology review

\section{Introduction}

The ocean is a source of significant energy resources that have so far remained almost untapped. The UK has the largest tidal resource in Europe [15], with a potential of around 21 TWh of tidal resource per year, exploitable by devices currently under development. This is almost $6 \%$ of the UK electricity consumption (per 2009) [16]. In the quest for replacing fossil fuelled power plants, new renewable power production must be developed, and marine current power is one of the fields that is expected to grow in the coming decades. [9] have made a prediction of ocean power installed capacity shown in Figure 1.

The aim of this paper is to provide an overview of the present marine current industry. Several other publications [17-24] look at turbine technologies, but without presenting details on drive train. In [25], several turbine technologies are presented and discussed, and drivetrain is discussed to a short extent, but the authors have found little information regarding choice of gears and generators. This study has a special focus on generators and drive trains. It is of great interest to understand generator technology requirements, in order to find optimal system

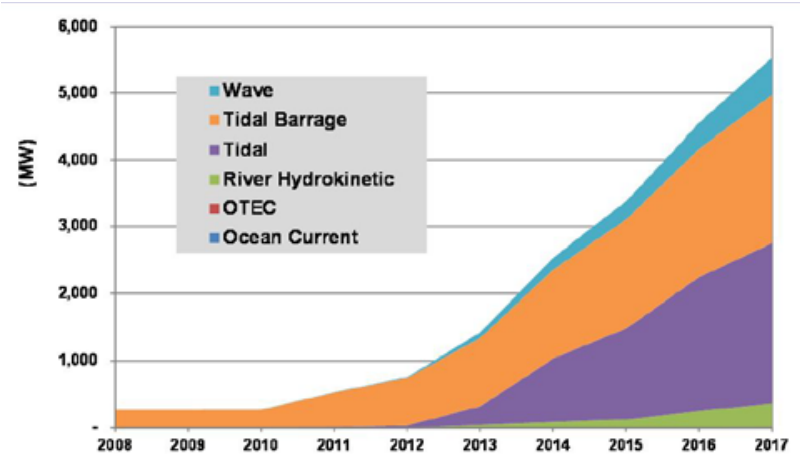

Figure 1: Predicted cumulative ocean power installed [9]

solutions, both from the generator providers' and the marine current industry's point of view. Trends for the different turbine types are pointed out, and challenges and future perspectives for the business in general are discussed.

Because of space limitations, not all devices can be presented. The devices that appear most promising and are most developed are included. The information is gathered from the major marine current energy device developers, mainly from their respective web sites.

\section{The industry}

The marine current industry is at a developing stage. Up until now, only a few installations have produced electric power to the grid. According to the European Marine Energy Centre (EMEC), more than 80 different tidal energy concepts exist [26]. Most of these are in a proofof-concept or a prototype stage, but a few, like Marine Current Turbine (Figure 9a) already have commercial products. [25] suggests that "the tidal power industry can be likened to the wind industry in the seventies, when a plethora of concepts were competing for supremacy." The development has been pushed by EMEC, a test and research centre in the Orkney Islands, along with several national renewable energy centres. A sign of maturing technology is the increased involvement by big industrial actors. In 2009, Alstom Hydro signed a licensing 
cooperation agreement with Clean Current Power Systems Incorporated, and Tidal Generation Limited became a wholly owned subsidiary of Rolls-Royce Plc. In 2012, Siemens acquired all the shares of tidal power company Marine Current Turbine (MCT) and ANDRITZ HYDRO increased its shareholding in Hammerfest Strøm, changing the name to ANDRITZ HYDRO Hammerfest.

\section{Technology}

Energy converters developed for marine currents are used in tidal currents, river streams or ocean currents. These are all harsh marine environments, and demand robustness, cost-effectiveness and time-limited maintenance. Note that the devices presented in the following section are not all commercially-ready devices.

\section{A. Oscillating Hydrofoils}

A vertically oscillating movement of a horizontal blade is utilized in the Pulse Tidal generator shown in Figure 2a. The swept area is rectangular rather than circular, which is beneficial for shallow sites [6]. According to [24], power is transmitted through hydraulic pressure to a gearbox and a generator housed in a steel nacelle above the waterline. A similar turbine, the Stingray, was developed by IHC Engineering Business and tested as early as 2003, but further development has stopped. Also here, the energy from the moving hydroplane was transferred via hydraulic pressure to an electric generator.

\section{B. Cross-axis turbine}

Cross-axis turbines may have either vertical or horizontal axis. An advantage of the vertical axis turbine is that water flow direction does not influence the output of the turbine. It is also possible to simplify maintenance by locating the main drivetrain above water.

Ponte di Archimede International Company have developed a floating vertically-axed turbine called Kobold [27]. In 2001 the company installed the first tidal turbine in the world to be connected to a national grid. The threebladed turbine is fully submerged underneath a floating platform which contains the rest of the powertrain (Figure 2b). The turbine shaft is connected to a gear, which is connected to a brushless synchronous machine [24, 28].

Neptune Renewable Energy [8] has developed a very different type of marine current energy converter with vertical axis, called the Proteus (Figure 3). A Venturi Duct accelerates the water speed towards a cross flow rotor with a vertical axis. The device is designed for shallow and estuarine locations. The turbine is connected to a DC
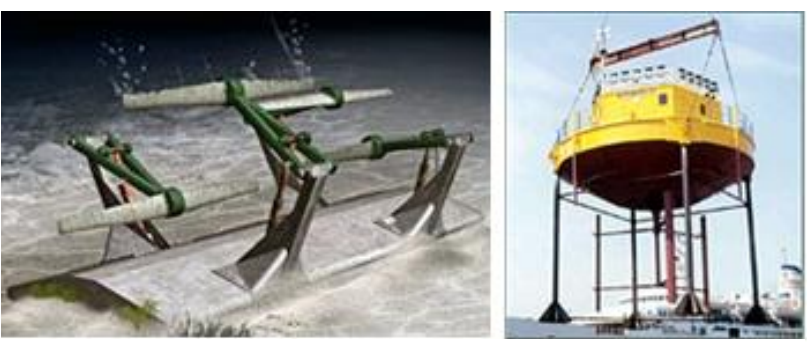

Figure 2: (a) The Pulse-Stream generator [6]

(b) The Kobold turbine[13]

https://doi.org/10.24084/repqj11.299

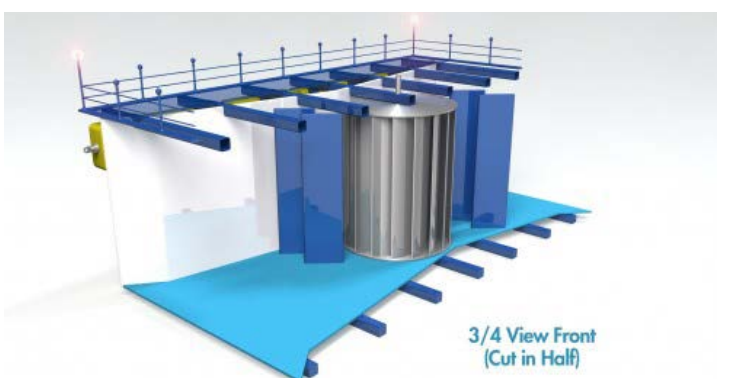

Figure 3: Neptune’s Proteus generator [8]

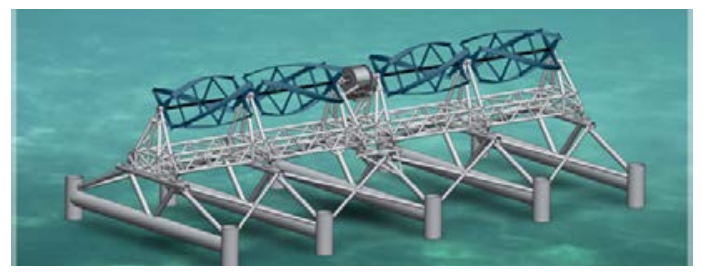

Figure 4: TidGen, by ORPC [5]

generator by a gearbox, and electric power is fed through cables to the shore, where the controls are situated.

Ocean Renewable Power Company has designed a modular turbine system with horizontal axis darrieus turbines (Figure 4). Small versions can be installed in rivers, bigger versions in shallow tidal streams, and the biggest version is to be installed in deep water tidal or ocean current sites. The turbines directly drive a permanent magnet generator, with no gear-exchange.

\section{Kite}

A marine current energy device which is significantly different from the rest is Minesto's Deep Green concept. It is a turbine attached to a wing (Figure 5), which moves in loops through the water, while attached to the seabed with a moving wire, like a kite [29]. The device moves through the water with a speed significantly higher than the water speed, reducing torque per power and hence weight and cost, compared to other device types. According to [16], a $1 \mathrm{~m}$ diameter turbine can generate $500 \mathrm{~kW}$, while a fixed turbine with the same capacity would be $30 \mathrm{~m}$ in diameter. The Carbon Trust's Marine Energy Accelerator project [16] states that "the device is sufficiently different from competing designs to potentially offer either a significantly lower cost of energy, or the ability to exploit an entirely new resource". The generator type used in the Deep Green turbine remains unknown for now.

\section{Helix screws}

Flumill's Helix screws' turbine is shaped like a screw, has only one moving part, and is slow-rotating. It is naturally buoyant and the tide itself shifts it's position with the flow and ebb. The turbine gearlessly drives a permanent magnet synchronous generator [2]. With a

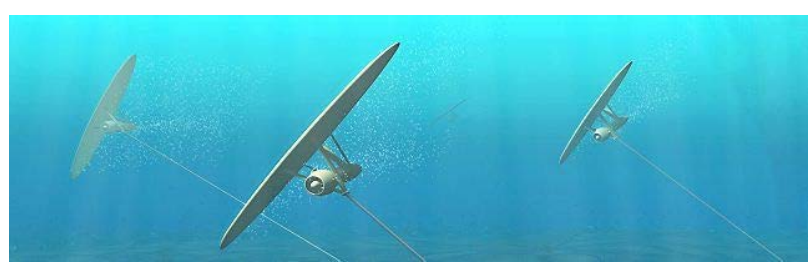

Figure 5: The kite-like turbine Deep Green [4] 


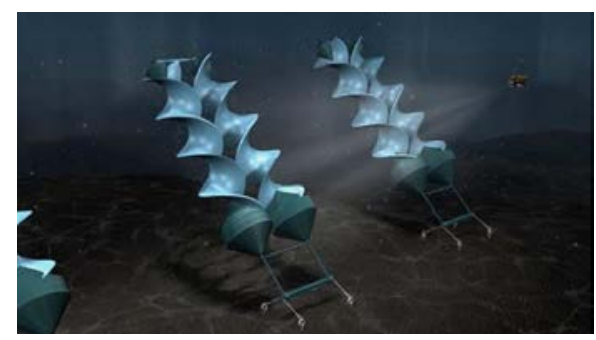

Figure 6: Flumill's Helix screws [2]

gearless topology, the PM generators are probably chosen based on the PM machine's good performance at low speeds.

\section{E. Enclosed tips (Venturi)}

There are several ducted turbines being developed, all of which seem to be gravity-based, i.e. mounted on the seabed. Lunar Energy's Rotech Tidal Turbine (Figure 7a) has a symmetrical venturi duct which accelerates the water speed through the duct and also aligns the current [3]. The drivetrain includes the turbine, a hub-mounted hydraulic pump, two hydraulic motors and a generator. The variable gear ratio supplied by the hydraulic system allows the turbine to run at variable speed while the generator runs at a constant $1500 \mathrm{rpm}$.

Open Hydro's Open-Centre Turbine (Figure 7b) and Alstom's Beluga 9 [26] both have an open centre, and the rim of the duct contains a permanent magnet synchronous generator, constituting gearless solutions. All of the above examples have bidirectional symmetrical turbines.

\section{H. Horizontal axis}

The majority of marine current energy devices currently being developed and tested are some form of horizontal axis devices. Within this category there is great variation. Some are mounted on the sea-bed while others are floating. Some are mounted alone and some have two or more turbines mounted on the same structure, where some may have pairs of rotors that contra-rotate.

\section{1) Single seabed-mounted}

Seabed-mounted turbines are often referred to as first generation devices. They can only be used at relatively shallow water depths. For deep sites, floating devices are the most attractive ones, as the water speed is fastest close to the surface.

Atlantis Resources Corporation's AR-1000 turbine (Figure 8a) has three blades and is fitted with a gearbox, a permanent magnet generator and a variable speed drive. The turbine has a rotation mechanism and turns as required with each tidal change [7]. A similar turbine is ANDRITZ
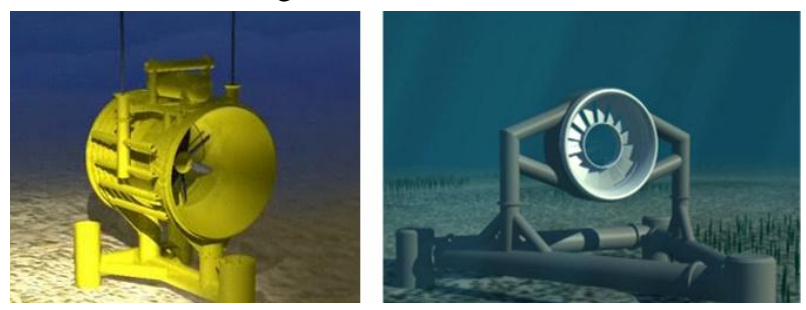

(a) Rotech Tidal Turbine [3] (b) Open Centre Turbine [11] Figure 7: Enclosed tips type turbines
HYDRO Hammerfest's HS1000 (Figure 8b). It is also a three-bladed turbine, but it captures the changing tides by pitching it's blades [12]. The first version of the turbine, the HS300 was made with an asynchronous machine, and the full scale version has a synchronous machine connected to the gearbox.

Voith Hydro Ocean Current Technologies (VHOCT) has developed a slightly different three-bladed turbine (Figure 8c). The blades do not pitch, and there is no yawmechanism; it is designed to be bidirectional. The permanent magnet generator is directly driven without the use of a gear [14]. Swanturbines' turbine is similar to VHOCT's in that it has direct drive and utilizes a permanent magnet generator. It does have a yaw mechanism that can turn the turbine [30].

Tidal Generation Limited has a turbine that also turns towards the tide. The powertrain includes a gear and an induction generator and the turbine is buoyant for the purpose of transportation [31]. Verdant Power has developed a turbine that is especially suited for river applications [32]. As it will only experience current from one direction, yaw is unnecessary. The turbine is geared and uses an induction generator.

\section{2) Multiple seabed-mounted:}

Marine Current Turbines have chosen a seabed-mounted structure for their SeaGen S (Figure 9a). Two two-bladed turbines are mounted on a crossbeam on a surfacepiercing tower support structure which can raise the turbines above water for repairs and maintenance. The blades are pitch-controlled and the mechanical energy is transferred through a gearbox to the asynchronous generator [33]. The company is also developing a turbine with the same powertrain for use at deeper locations, the SeaGen U (Figure 9c), with a structure that will be able to raise the turbines out of the water for maintenance. Another device comprising of several turbines is DeltaStream, developed by Tidal Energy ltd. Three threebladed turbines are mounted on a single, triangular frame (Figure 9b). The hub of each turbine can rotate. It is connected through an epicyclic gearbox to an induction generator [34].

\section{3) Floating:}

Floating marine current turbines are made for deep waters and are often referred to as second generation devices. They may be totally submerged, or part of the structure floats above water (Figure 10). These devices usually don't need a yaw mechanism, as the tide will pull the turbine into the correct position. Floating devices are more readily accessible than seabed-mounted ones, a significant advantage which can reduce O\&M costs.

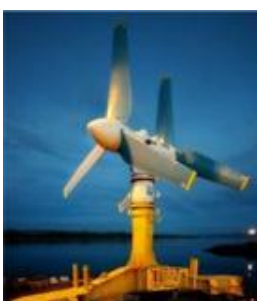

(a) AR-1000 [7]

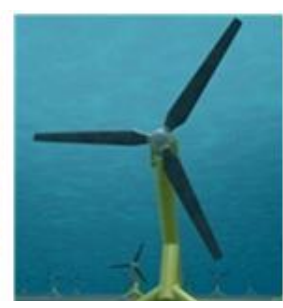

(b) HS 1000 [12]

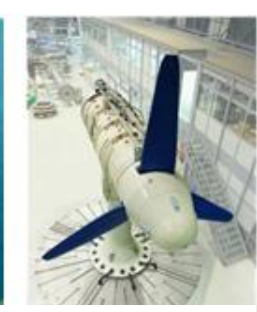

(c) VHOCT [14]
Figure 8: Horizontal axis seabed mounted turbines 

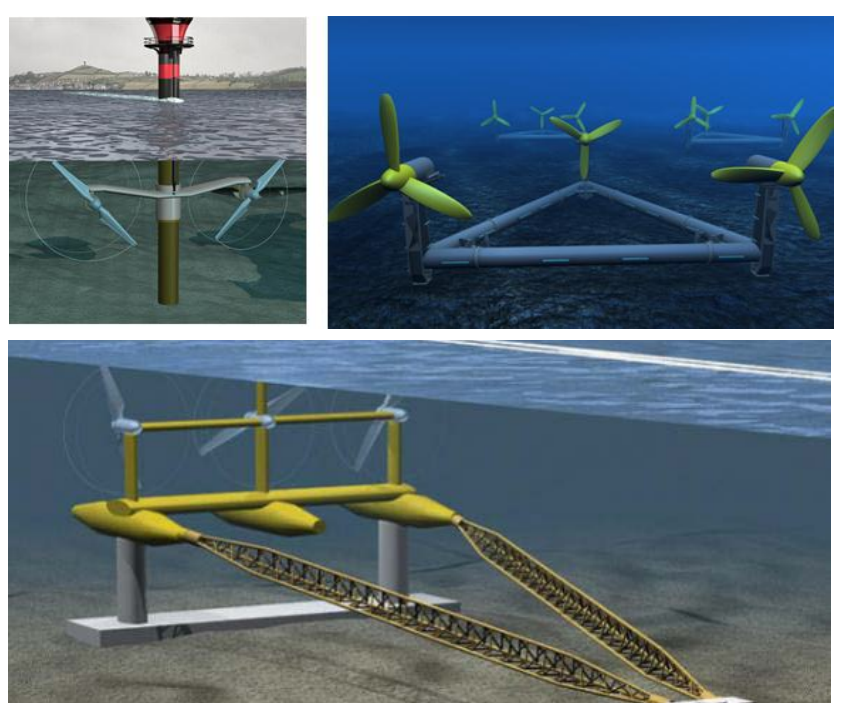

(a) SeaGen S [1] (b) DeltaStream [10]

(c) SeaGen U [1]

Figure 9: Multiple horizontal axis turbines

Oceanflow Energy's three-bladed Evopod ${ }^{\mathrm{TM}}$ comes in single, twin and multiple turbines [35]. The structure floats partly above the water. The blades are fixed, and the swivel mooring and power export solution is disconnectable. The powertrain includes a gear and a permanent magnet generator. Another floating device is SMD Hydrovision's TidEl, a naturally buoyant device consisting of two two-bladed turbines connected by a rigid structure (Figure 10a). The development of TidEl is stopped for the time being. The powertrain was not yet developed for the full scale device. Scot-renewables' marine current turbine consists of a steel tube that floats on the surface and two two-bladed rotors mounted on arms that fold up next to the tube in especially rough weather and during transportation (Figure 10b). It has a passive yaw system and fixed pitch blades. The powertrain is still under evaluation, but will, for the next generation, contain a gearbox. CoRMaT, the tidal generator developed by Nautricity, has a turbine with two closely spaced contrarotating rotors. This gives less wake-effect, causing less environmental impacts and the possibility to have an increased density of devices [36]. The device is neutrally buoyant and has a passive yaw. Within the nacelle there is a permanent magnet generator which is driven by the two

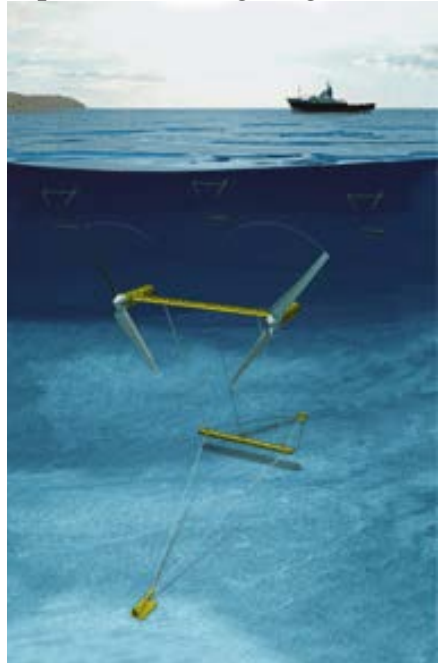

(a) TidEl [37]

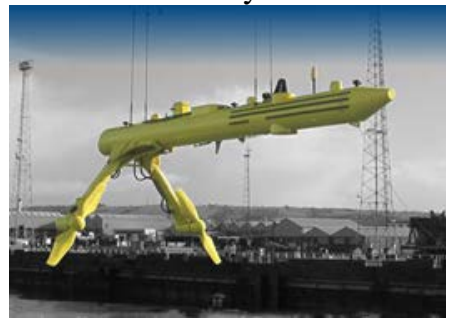

(b) Scotrenewables [38]

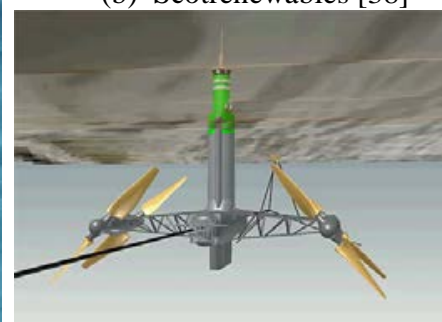

(c) Morild II [39]
Figure 10: Floating turbines rotors. The relative speed within the generator is twice that of each of the rotors, reducing the torque requirement and thereby the size of the generator. Hydra Tidal Energy Technology has developed a turbine system called Morild II, with 4 adjustable rotors with a total of 8 blades (Figure 10c). The device is floating, and also here, two of the turbines rotate in the opposite direction of the other two. The blades are pitched for bidirectional use. From the turbine rotation there is a hydraulic transmission to two synchronous generators. The generators run at a constant speed while the turbines can have a variable speed.

\section{Generator choice}

The information concerning generator type is not readily available from all developers. Some share this information on their web-pages, others have revealed it through other channels, while for some, it is impossible to find. Information on type of gear and gear ratio is almost non-existent. The lack of information may be because some are still undecided, others may want to keep it secret, knowing that the competition in the market is strong.

\section{A. Trends}

\section{Hydrofoils}

The slow movement of the hydrofoil with large forces involved results in very high demands for the systems transferring mechanical energy to electrical energy. A hydraulic system, as used in both hydrofoils mentioned here, is well suited for this kind of application.

\section{Enclosed tips}

For the enclosed tip turbines, directly driven PM generators seem to be the preferred solution. Similar generator types are also used for small hydroelectric turbines in rivers, like Andritz' Hydromatrix turbines [40] and VLH's Kaplan turbine [41]. With the generator placed on the rotor circumference, a direct drive solution is an obvious choice.

\section{Horizontal axis - seabed-mounted}

For seabed-mounted turbines there is no clear pattern when it comes to drive trains. Most of them are geared, but some are direct driven. Those which are direct driven seem to utilize PM generators. Both synchronous and asynchronous generators are in use, but it may seem like some asynchronous generators are being replaced by synchronous generators in later turbine versions.

\section{Horizontal axis - floating}

Compared to surface-mounted devices, floating turbines have the added constraint of keeping weight as low as possible. This may be the reason why almost all manufacturers have chosen geared or hydraulic solutions in their powertrain. A direct drive would also in most cases require a prototype generator. John McGlynn in Scotrenewables Tidal Power Ltd explains that since the turbine is a prototype, they try not to us prototype components as well to reduce the risk of failure. 


\section{General trends}

The general trend is that several drive train options are being tested. For manufacturers seeking to minimize risk for prototype turbines, prototype generators are avoided, and induction generators seem to be the preferred choice. Most powertrains include a gearbox, reducing the size and weight of the generator. Especially for floating turbines, this seems to be the trend. For the direct-drive systems, particularly for the enclosed tip-type turbines, PM generators are preferred.

\section{B. Challenges}

The marine current industry is at an early stage of development. The business is characterized by prototype building and new ideas being brought forward. In such a setting, reliability is of great importance. Manufacturers do not want to put their new tidal turbine in the sea for the first time to find that the generator doesn't work properly. This is a significant risk if the generator is also a prototype. But some marine current turbines require properties that are not common for off-the shelf products. Besides, the optimal combination of compactness, high efficiency and high reliability during the product's lifetime are characteristics that may not be available in thoroughly tested machinery. The manufacturers will therefore have to face the trade-off between risking a malfunction in the generator and using a generator that is not optimised for the turbine. This technology review shows that different manufacturers choose different strategies. The companies that prefer the risk-evasive option may want to alter their drive train design once turbine functionality is proven. Then they can focus on optimising the rest of the system.

Because marine current energy converters are always placed under water, and often far from docks and workshops, it is of utmost importance to design a system that requires as little maintenance as possible, and that has the lowest possible risk of failure. This is a problem for all components in the turbine, and the manufacturers try to keep the number of risky components to a minimum. This includes all moving parts, like seals, gears, breaks etc. Machines with brushes are not desirable in such underwater structures, because brushes are a common source of failure, although brush quality has improved greatly in the last decades. Removing gears is also of great interest. This increases the size of the generator significantly.

The marine current industry will only survive if it becomes economically viable. The cost of installing, maintaining and operating the power system must not exceed the income from the sale of electricity to the grid. Looking at the cost side of the picture, the manufacturers need to find ways of producing energy as cheaply as possible. New ideas may help reduce the cost of cables, converters, gears, breaks, generators or other parts of the system. As the business grows, production cost will decrease as produced volumes increase. The income side of the picture is more difficult to predict. Energy prices are unpredictable, and depend on politics and oil and gas prices among other things. Government support may also be sporadic, and varies greatly from country to country. The UK has one of the best support policies for ocean energy, and the effect of that can be seen today. The tidal power developments are much more frequent in the UK than in other countries with significant tidal resources. As the situation is today, one of the most important jobs for the marine current industry is therefore to work towards governments to ensure sufficient government support, at least through this crucial initial stage for the business in general.

\section{Future perspectives}

The future of marine current energy utilisation depends on economics. If energy prices are high and government support is sufficient, we will most likely see a boom in installation of turbines in the coming decades. But with today's framework conditions the revenue will most likely be marginal; hence it is up to the manufacturers to come up with cost-effective solutions.

Every part of the system should be optimised with respect to both cost and performance. This study has revealed that some manufacturers have chosen generators based on reliability and commercial availability so far. Will they keep their design when the big arrays of devices are built, or will they do a new iteration step to optimize their design?

\section{Conclusion}

The marine current energy industry moves at a fast pace, with many different turbine technologies competing for the possibility of becoming the preferred solution. This study has given an overview of some of the most promising turbines and the appurtenant generators chosen.

The great majority of devices are of the horizontal axis type with two or three blades transferring mechanical energy to a central hub. There are also a few similar designs with enclosed tips. For other types of design, like cross-axis turbines, the design variation is great, which might indicate that they have not found a design that can compete with the horizontal axis designs.

As new technology is being tested on prototype devices, many developers choose geared solutions with off-the shelf generators, reducing the number of prototype elements to a minimum. Both induction machines and synchronous machines are being used. Devices that have no choice but to use prototype generators, like the ducted devices prefer PM synchronous machines, while some have chosen hydraulic options. Some developers choose to use gearless solutions, and these tend to utilize PM generators.

It is interesting to see so many marine current developers choose geared solutions, when the wind energy section has been shifting towards direct drive. Especially since maintenance and repair is even more costly in underwater equipment. The cause could be that the expected lifetime of mechanical gears has increased lately. 
So far, no big arrays of marine current devices have been built. The developers who have had the technology proven in full scale prototype devices now have the opportunity to polish their design and do further optimisations before proceeding to full scale. It will be interesting to see whether they will keep their drivetrain solutions in their final products or replace them with more optimised equipment.

\section{References}

1. MCT. http://www.marineturbines.com/. [Online] [cited October 2012].

2. Flumill. http://www.flumill.com/. [Online] [cited October 2012].

3. Lunar Energy. http://www.lunarenergy.co.uk/. [Online] [cited October 2012].

4. Minesto. http://www.minesto.com/. [Online] [cited October 2012].

5. Ocean Renewable Power Company. http://www.orpc.co/. [Online] [cited October 2012].

6. Pulse Tidal. http://www.pulsetidal.com/. [Online] [cited October 2012].

7. Atlantis Resources Corporation. http://www.atlantisresourcescorporation.com/. [Online] [cited October 2012].

8. Neptune Renewable Energy. http://www.neptunerenewableenergy.com/. [Online] [cited October 2012].

9. Asmus, P., Gauntlett, D., Hydrokinetic and Ocean Energy: Renewable Power Generation from Ocean Wave, Tidal Stream, River Hydrokinetic, Ocean Current, and Ocean Thermal Technologyh, 2012, Pike Research.

10. Tidal Energy. http://www.tidalenergyltd.com/. [Online] [cited October 2012].

11. Open Hydro. http://www.openhydro.com. [Online] [cited October 2012].

12. Hammerfest strøm. http://www.hammerfeststrom.com/. [Online] [cited October 2012].

13. Aquatera Ltd. http://www.aquatera.co.uk/search/report_project.asp ?ID1=224. [Online] [cited October 2012].

14. Voith Hydro Ocean Current Technologies. http://voith.com/. [Online] [cited October 2012].

15. Brooks, R., The World Offshore Energy Renewable Report 2004-2008, 2004, DTI's 2010 Target Team, UK.

16. Accelerating marine energy, 2011, Carbon Trust.

17. Lago, L.I., F.L. Ponta, and L. Chen, Advances and trends in hydrokinetic turbine systems. Energy for Sustainable Development, 2010. p. 287-296.

18. Mueller, M. and R. Wallace, Enabling science and technology for marine renewable energy. Energy Policy, 2008. p. 4376-4382.

19. Bedard, R., Survey and Characterization Tidal In Stream Energy Conversion (TISEC) Devices, 2005, EPRI.

20. Bahaj, A.S., Generating electricity from the oceans. Renewable and Sustainable Energy Reviews, 2011. p. 3399-3416.

21. Güney, M.S. and K. Kaygusuz, Hydrokinetic energy conversion systems: A technology status review.
Renewable and Sustainable Energy Reviews, 2010. p. 2996-3004.

22. Khan, M.J., et al., Hydrokinetic energy conversion systems and assessment of horizontal and vertical axis turbines for river and tidal applications: $A$ technology status review. Applied Energy, 2009. p. 1823-1835.

23. Rourke, F.O., F. Boyle, and A. Reynolds, Marine current energy devices: Current status and possible future applications in Ireland. Renewable and Sustainable Energy Reviews, 2010. p. 1026-1036.

24. Hardisty, J., The Ananlysis of Tidal Stream Power 2009: John Wiley \& Sons Ltd.

25. King, J. and T. Tryfonas. Tidal stream power technology - State of the art. 2009. Bremen.

26. EMEC. http://www.emec.org.uk/. [Online] [cited October 2012].

27. Ponte di Archimede. http://www.pontediarchimede.it/language us/. [Online] [cited October 2012].

28. Calcagno, G., et al. Experimental and numerical investigation of an innovative technology for marine current exploitation: The Kobold turbine. 2006. San Francisco, CA.

29. Hjerpe, N. and A. Signahl, Deep Green i oceana strömmar - en konceptstudie, in Institutionen för ekonomisk ock industriell utveckling, Linköpings universitet.

30. Swanturbines. http://www.swanturbines.co.uk/. [Online] [cited October 2012].

31. Tidal Generation. http://www.tidalgeneration.co.uk/. [Online] [cited October 2012].

32. Verdant Power. http://verdantpower.com/. [Online] [cited October 2012].

33. Douglas, C.A., G.P. Harrison, and J.P. Chick, Life cycle assessment of the Seagen marine current turbine. Proceedings of the Institution of Mechanical Engineers Part M: Journal of Engineering for the Maritime Environment, 2008. p. 1-12.

34. DeltaStram Tidal Energy Solution, 2012, Tidal Energy Limited.

35. Oceanflow Energy. http://www.oceanflowenergy.com/. [Online] [cited October 2012]

36. Nautricity. http://www.nautricity.com/. [Online] [cited October 2012].

37. Treehugger.com: TidEl Harnesses Lunar Energy? [Online] [cited October 2012]; Available from: http://www.treehugger.com/renewable-energy/tidelharnesses-lunar-energy.html.

38. Scotrenewables. http://www.scotrenewables.com/. [Online] [cited October 2012].

39. Hydra Tidal. http://www.hydratidal.no/. [Online] [cited October 2012].

40. ANDRITZ HYDRO. http://www.andritz.com/hydro/hy-others-andritzhydro/hyhydromatrix/hy-hydromatrixtechnology.htm. [Online] [cited October 2012].

41. VLH. http://www.vlh-turbine.com/. [Online] [cited October 2012]. 